\title{
Anesthetic and obstetric considerations in a parturient with Klippel-Trenaunay syndrome
}

\author{
[Considérations anesthésiques et obstétriques chez une parturiente atteinte du
}

syndrome de Klippel-Trenaunay]

Michael J. Sivaprakasam MD, ${ }^{*}$ James A. Dolak MD PhD†

Purpose: To explain the considerations governing the anesthetic management of pregnant patients with Klippel-Trenaunay syndrome (KTS). Klippel-Trenaunay syndrome is a congenital vascular disease characterized by cutaneous hemangiomas, venous varicosities, and limb hypertrophy; and is associated with both hemorrhagic and thrombotic complications. The importance of this diagnosis, including the presence of neuraxial vascular anomalies, is often under-appreciated by both obstetric and anesthesia providers. While regional anesthetic management of patients with KTS has been discussed by others, we present a case in which regional anesthesia presented an unwarranted risk to the patient.

Clinical features: An obese, 18-yr-old parturient with a fetus in the breech position underwent Cesarean delivery at 35 weeks gestation secondary to evolving preeclampsia. Unfortunately, no neurovascular imaging of this patient's spine was available. The patient underwent an attempted external cephalic version, a failed obstetric induction, and, ultimately, a Cesarean delivery under general anesthesia. The resulting infant was without any stigmata of KTS. Both mother and infant did well during the course of their hospitalization, and were discharged home without incident.

Conclusions: The posterior cutaneous hemangiomas of KTS may be associated with underlying epidural and subdural vascular malformations. Disruption of these vascular anomalies during regional anesthesia may lead to neuraxial hematoma formation, which may be further compounded by a consumptive coagulopathy observed in some cases of KTS. If neuraxial vascular anomalies cannot be ruled out radiographically, regional anesthesia should be avoided. Additionally, regardless of the anesthetic technique chosen, the coagulation profile of these patients should be verified for signs of coagulopathy.
Objectif : Expliquer la démarche anesthésique considérée chez des patientes enceintes atteintes du syndrome de (SKT). Le syndrome de Klippel-Trenaunay est une maladie vasculaire congénitale caractérisée par des hémangiomes cutanés, des varicosités veineuses et l'hypertrophie d'un membre. Il est associé à des complications hémorragiques et thrombotiques. L'importance de ce diagnostic, dont la présence d'anomalies vasculaires neuraxiales, est souvent sous-estimée par les obstétriciens et les anesthésiologistes. L'anesthésie régionale de patients atteints du SKT a été discutée par d'autres; nous présentons un cas où l'anesthésie régionale $a$ présenté un risque injustifié pour la patiente.

Éléments cliniques: Une parturiente obèse de 18 ans, dont le fœtus se présentait par le siège, a subi une césarienne à 35 semaines de grossesse à la suite d'une prééclampsie évolutive. Malheureusement, aucune imagerie neurovasculaire de la colonne n'était disponible. La patiente a subi une tentative de version céphalique externe, l'échec d'une induction obstétrique et, finalement, une césarienne sous anesthésie générale. L'enfant est né sans stigmate du SKT. L'hospitalisation a été sans incident pour la mère et l'enfant qui ont reçu leur congé.

Conclusion : Les hémangiomes cutanés postérieurs liés au SKT peuvent être associés à des malformations vasculaires péridurales et sous-durales initiales. La rupture de ces anomalies vasculaires pendant l'anesthésie régionale peut conduire à la formation d'hématome neuraxial qui pourraient être combinée ensuite à une coagulopathie intravasculaire disséminée observée chez certains cas de SKT. Si les anomalies vasculaires neuraxiales ne peuvent être exclues par radiographie, l'anesthésie régionale devrait être évitée. De plus, peu importe la technique anesthésique choisie, le profil de coagulation de ces patientes devrait être vérifié à la recherche de signes de coagulopathie.

From the Departments of Anesthesiology, ${ }^{*}$ St. Edward's Mercy Medical Center, Fort Smith, Arkansas; and General Anesthesiology, $†$ The Cleveland Clinic Foundation, Cleveland, Ohio, USA.

Address correspondence to: Dr. James A. Dolak, Department of General Anesthesiology, E31, The Cleveland Clinic Foundation, 9500

Euclid Avenue, Cleveland, Ohio 44195, USA. Phone: 216-444-0257; Fax: 216-444-9247; E-mail: dolakj@ccf.org

Departmental attribution: Department of General Anesthesiology, The Cleveland Clinic Foundation, Cleveland, Ohio.

Financial support: None.

Accepted for publication December 7, 2005.

Revision accepted December 19, 2005.

Competing interest: None declared. 
K

LIPPEL-TRENAUNAY syndrome (KTS) is a congenital, neuroectodermal disorder characterized by cutaneous capillary malhypertrophy - often with associated arteriovenous mat formations (AVMs). ${ }^{1}$ A dermatomal association exists between the cutaneous hemangiomas and neuraxial vascular malformations. ${ }^{2}$ Commonly, there is persistence of abnormal superficial veins in affected limbs with hypoplasia of the deep veins. Finally, thrombosis, consumptive coagulopathy, and hemorrhage can be associated with KTS. ${ }^{3}$ We present a case where regional anesthesia presented an unwarranted risk to a patient with KTS. The patient consented to publication of this report and the accompanying photographs.

\section{Case report}

An obese, 18-yr-old, $155 \mathrm{~cm}, 100 \mathrm{~kg}$, primigravida with KTS was admitted at 35 weeks gestation with a diagnosis of preeclampsia. Her fetus was noted to be in a frank breech presentation, with a normal fetal heart rate. She had no known drug allergies; and had been on aspirin thromboprophylaxis until three days prior to admission. Additionally, she reported a history of severe bleeding following even minor trauma to her left leg and back.

Physical examination showed prominent vascular malformations over her left leg (Figure 1) and on her lower back extending to the eleventh thoracic dermatome (Figure 2). No vascular lesions were noted in the airway, birth canal, or over the abdomen. Airway examination revealed a Mallampati score of 2, adequate thyromental distance and mouth-opening, and free range of motion of the neck. Laboratory studies revealed a hematocrit of $33.7 \%$, platelet count of $222 \times$ $10^{3} \cdot \mathrm{mL}^{-1}$, prothrombin time of $9.6 \mathrm{sec}$ (normal range $8.7-12.2 \mathrm{sec})$, international normalized ratio of 0.93 (normal range 0.9-1.2), and partial thromboplastin time of $25.9 \mathrm{sec}$ (normal range $23-34 \mathrm{sec}$ ). Given the extent of the vascular malformations, the history of severe bleeding with minor trauma, the likelihood of deep communication with neuraxial vessels, and the presence of a manageable airway in this patient, we recommended systemic opioid analgesia for labour pain and general anesthesia for Cesarean delivery.

Magnetic resonance imaging (MRI) obtained earlier in pregnancy showed an absence of deep veins in the left leg, along with the presence of prominent veins in the left pelvis and groin. Unfortunately, the magnetic resonance imaging did not include imaging of the spine. Based upon the MRI findings, a vascular surgery consultation recommended vaginal delivery, as any interruption of superficial venous drainage from

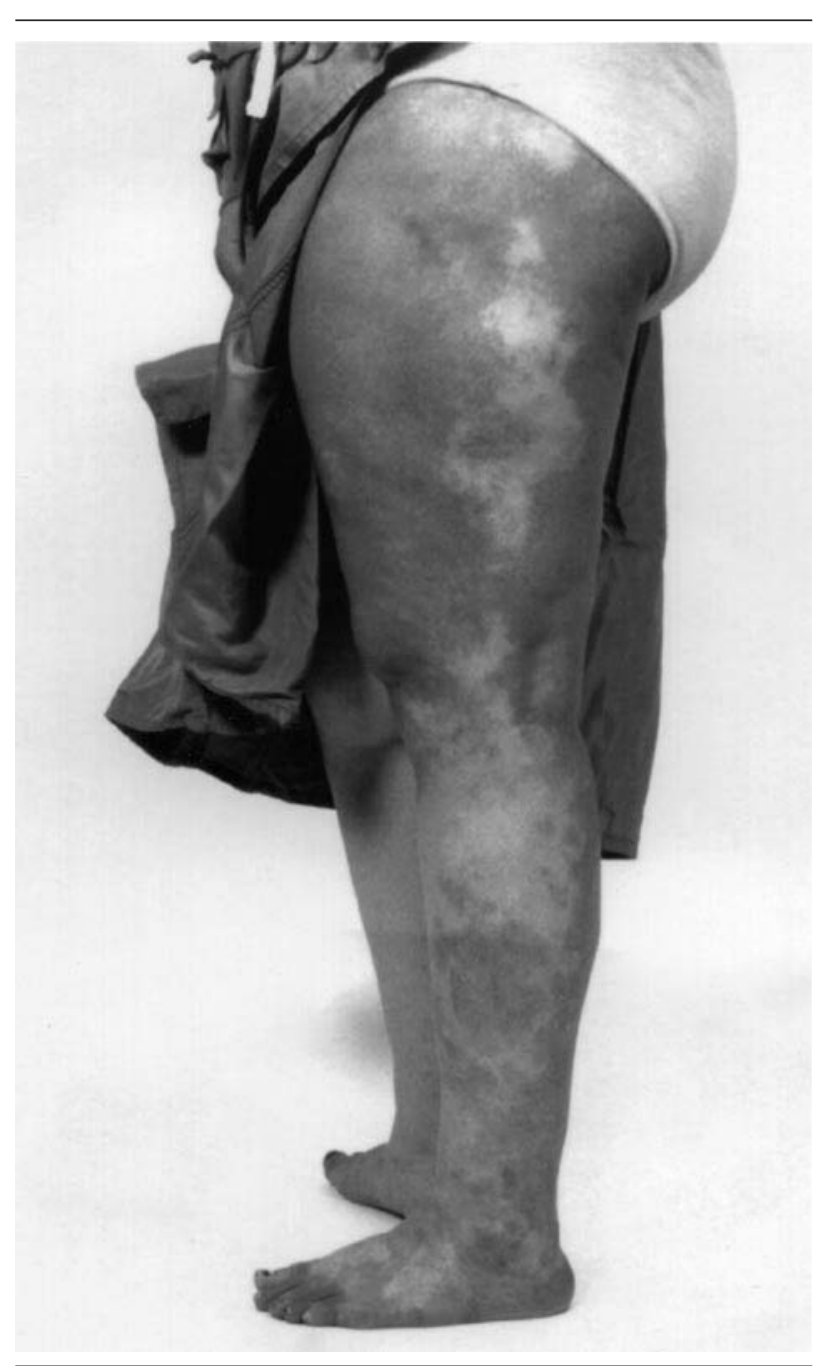

FIGURE 1 Patient's left leg showing extensive involvement with hemangiomatous lesions.

the left leg by Cesarean delivery had the potential to end in limb loss.

Intravenous magnesium sulfate was started for seizure prophylaxis, which also provided adequate blood pressure control. Expedited delivery was chosen before any maternal or fetal compromise occurred from preeclampsia. An attempted external version failed to convert the fetal position to a cephalic presentation, after which labour was induced with iv oxytocin in an effort to allow a vaginal breech extraction. Despite adequate uterine contractions, the patient showed no sign of cervical dilation over the next $24 \mathrm{hr}$. A decision was made to proceed with Cesarean delivery, and upon reconsultation, the vascular surgery service stated that a vertical, midline incision would probably 


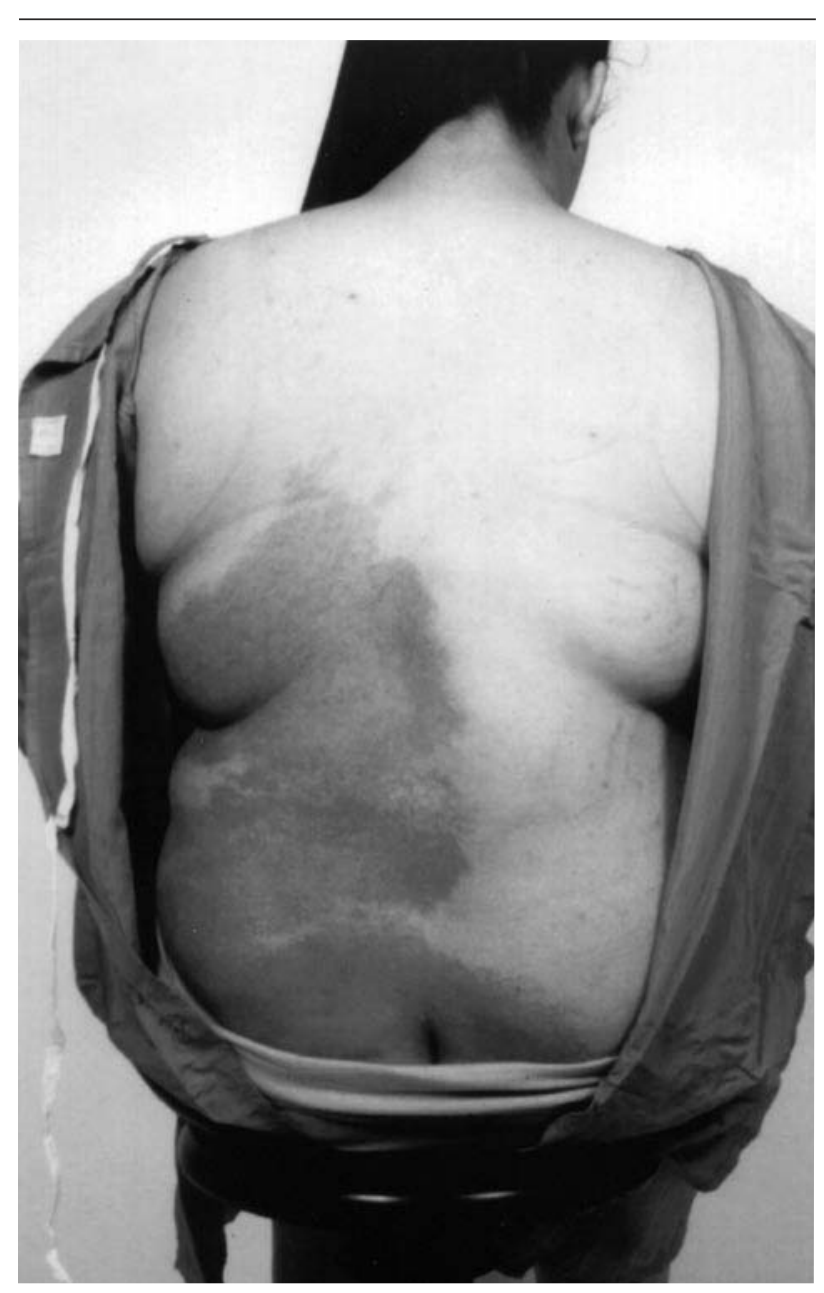

FIGURE 2 Back and buttocks are extensively involved with hemangiomatous lesions. Note extension across to right side in thoracic, lumbar, and sacral regions.

avoid vascular compromise to the patient's left leg. Aspiration prophylaxis with metoclopramide $(10 \mathrm{mg}$ $i v)$, famotidine ( $20 \mathrm{mg} i v)$, and oral sodium citrate (30 $\mathrm{mL}$ ) was provided, and the patient was transferred to the operating room.

In the operating room, two $16-\mathrm{G}$ iv catheters were inserted, and a standard obstetric general anesthetic was administered uneventfully. Prior to induction, the patient was pretreated with labetalol $(10 \mathrm{mg} i \mathrm{v})$, to prevent any untoward blood pressure response upon induction and intubation. A vertical, mid-line incision was made with special care taken to avoid interrupting any vascular anomalies. A $2199 \mathrm{~g}$, female infant with Apgar scores of 8 and 9 was delivered through a low transverse uterine incision.

The patient had an unremarkable postoperative course. Systemic narcotics provided pain control, and heparin $(5,000 \mathrm{U} s c$ bid) provided thromboprophylaxis. On the third hospital day, heparin therapy was discontinued, oral aspirin therapy was resumed, and the patient was discharged home with her infant.

\section{Discussion}

Klippel-Trenaunay syndrome is a rare disorder, and is even rarer as a complicating feature of pregnancy. Klippel-Trenaunay syndrome was first described in 1900 by the French physicians Klippel and Trenaunay. ${ }^{4}$ It is characterized by the presence of varicosities and cutaneous hemangiomas involving an often hypertrophied extremity. Weber, in 1918, noted the association of this syndrome with the presence of AVMs, ${ }^{5}$ and the name Klippel-Trenaunay-Weber syndrome is sometimes used to describe this symptom complex. Other features of this syndrome may include: scoliosis, hyperhidrosis, neuraxial hemangiomas, and occasional coagulopathy. ${ }^{6,7}$

The obstetric plan was complicated by hemorrhagic and thrombotic considerations. An increased circulating blood volume of pregnancy, in combination with venous obstruction by the gravid uterus, may cause marked engorgement of visceral and/or cutaneous vascular malformations, predisposing them to rupture with ensuing hemorrhage. This risk may be further increased by Valsalva maneuvers during the second stage of labour. Hemorrhagic complications may also arise as a result of pelvic varicosities being injured by traumatic vaginal delivery or Cesarean delivery. ${ }^{8,9}$ Consideration of the location of pelvic or vaginal varicosities may determine which of these modes of delivery is safest, and as in our case, may even suggest a recommended operative approach if Cesarean delivery is undertaken. Additionally, these patients are at physiological risk of hemorrhage secondary to a low-grade consumptive coagulopathy that can be seen with AVMs. ${ }^{9-11}$ The net effect would be to exacerbate any bleeding secondary to vessel injury. Paradoxically, KTS patients are also at risk of thromboembolic complications, with a reported incidence of venous thromboembolism as high as $22 \% .{ }^{12}$ Deep vein hypoplasia of the lower extremities, along with the increased blood volume of pregnancy and relative obstruction of venous return by the gravid uterus, can lead to edema and vascular sludging. Additionally, as the varicosities are at risk of minor trauma, and most KTS patients would be expected to be in a hypercoagulable state secondary to pregnancy, the classic predisposing factors for venous thrombosis - stasis, hypercoagulability, and vascular injury - are often met in these patients. Finally, disruption of the superficial draining veins of 
a leg during Cesarean delivery may result in eventual amputation due to unrelieved venous engorgement.

The anesthetic plan is also complicated by the existence of vascular anomalies, along with the possibility of a consumptive coagulopathy. In the presence of a normal coagulation profile, with no evidence of neuraxial vascular anomalies, it is possible to safely undertake regional anesthesia in these patients. ${ }^{6,7,10,11}$ However, of particular relevance here is the frequently demonstrated connection between cutaneous vascular malformations and central nervous system hemangiomas in the same dermatome (much of her back was involved with vascular malformations, and no neurovascular imaging of her spine was available). Thus there was a distinct possibility of traumatizing a central nervous system malformation during regional anesthesia, with a resulting neuraxial hematoma and possible development of paraplegia. Others also feel that neuraxial anesthesia presents an unwarranted risk in the pregnant KTS patient who presents in labour without prior neurovascular imaging studies. ${ }^{13}$ However, even general anesthesia can be complicated by the presence of various vascular abnormalities. One report described vascular abnormalities of the facial veins and jugular system in a KTS patient. ${ }^{1}$ With this presentation, endotracheal intubation may be more difficult due to increased upper airway edema from vascular congestion, or by massive airway hemorrhage should a vascular structure be traumatized. Finally, poor control of hemodynamic responses to laryngoscopy could conceivably lead to a cerebrovascular accident from rupture of an intracranial AVM. These hemorrhagic complications would be exacerbated in the presence of coagulopathy.

We realize that the KTS patient could present with a difficult airway, either primarily or as a result of KTS, along with vascular abnormalities of the neuraxis. In such a case, we would still undertake a general anesthetic, but would secure the airway using awake fibreoptic intubation techniques. However, if significant vascular malformations were observed or known to be present in the airway, we would have considered the use of a laryngeal mask airway with continuous cricoid pressure, ${ }^{14}$ in an effort to minimize airway trauma and avoid serious airway hemorrhage.

Optimal management of the pregnant KTS patient requires good communication between the obstetric, anesthesia, and vascular services. While the communication between services was excellent after presentation of this patient to the labour and delivery ward, the significance of this syndrome to the anesthesiologist (i.e., neuraxial hemangioma disruption followed by potential hematoma formation) was initially overlooked by our obstetric colleagues, who did not request an antepartum anesthesia consultation. The absence of neuraxial imaging precluded the use of regional anesthesia in this patient, although the extensive posterior involvement of the skin with hemangiomatous lesions probably contraindicated such an approach. Fortunately, the patient's airway was uninvolved by the disease process, and we were able to induce general anesthesia safely. This report highlights potential complications and the importance of communication between medical services regarding the obstetrical patient with large cutaneous hemangiomas.

\section{References}

1 Berry SA, Peterson C, Mize W, et al. Klippel-Trenaunay syndrome. Am J Med Genet 1998; 79: 319-26.

2 Alexander MJ, Grossi PM, Spetzler RF, McDougall CG. Extradural thoracic arteriovenous malformation in a patient with Klippel-Trenaunay-Weber syndrome: case report. Neurosurgery 2002; 51: 1275-8.

3 Pollack RN, Quance DR, Shatz RM. Pregnancy complicated by the Klippel-Trenaunay syndrome. A case report. J Reprod Med 1995; 40: 240-2.

4 Klippel M, Trenamnay P. Du nœvus variqueux ostéohypertrophique. Arch Gen Med Paris 1900; 3: 611-72.

5 Weber FP. Hæmangiectatic hypertrophy of limbs. Congenital phlebarteriectasis and so-called congential varicose veins. Br J Child Dis 1918; 15: 13-7.

6 Christie IW, Abkine PA, Holland RL. Central regional anaesthesia in a patient with Klippel-Trenaunay syndrome. Anaesth Intensive Care 1998; 26: 319-21.

7 Gaiser RR, Cheek TG, Gutsche BB. Major conduction anesthesia in a patient with Klippel-Trenaunay syndrome. J Clin Anesth 1995; 7: 316-9.

8 Hergesell K, Kroger K, Petruschkat S, Santosa F, Herborn C, Rudofsky Gl. Klippel-Trenaunay syndrome and pregnancy. Int Angiol 2003; 22: 194-8.

9 Hulsman R. Complications des localisations pelviennes dans le syndrome de Klippel-Trenaunay. Phlebologie 1991; 44: 404-6.

10 de Leon-Casasola OA, Lema MJ. Anesthesia for patients with Sturge-Weber disease and Klippel-Trenaunay syndrome. J Clin Anesth 1991; 3: 409-13.

11 Dobbs P, Caunt A, Alderson TJ. Epidural analgesia in an obstetric patient with Klippel-Trenaunay syndrome. $\mathrm{Br}$ J Anesth 1999; 82: 144-6.

12 Aggarwal K, Jain VK, Gupta S, Aggarwal HK, Sen $J$, Goyal Vl. Klippel-Trenaunay syndrome with a lifethreatening thromboembolic event. J Dermatol 2003; 30: $236-40$.

13 Felten ML, Mercier FJ, Bonnet V, Benhamou D. Analgésie obstétricale chez des patientes atteintes 
d'un syndrome de Klippel-Trenaunay. Ann Fr Anesth Réanim 2001; 20: 791-4.

14 Han TH, Brimacombe J, Lee EJ, Yang HS. The laryngeal mask airway is effective (and probably safe) in selected healthy parturients for elective cesarean section: a prospective study of 1067 cases. Can J Anesth 2001; 48: 1117-21. 